\title{
Introduction: priority setting, equitable access and public involvement in health care
}

\section{Introduction}

Priority setting in health care is now at the centre of policy and political attention in many parts of the world. More countries move towards attaining universal health care, but many struggle to ensure the sustainability of their health systems under competing demands from patients, a steady increase in medical advances and limited health care budgets. Where trade- offs are inevitable, a process that uses evidence to set priorities is essential. The most visible expression of this central role is to be found in the establishment of health technology assessment (HTA) agencies with the responsibility for determining what counts as value for money in health care and what priority should be given to particular interventions. Although the oldest of such bodies, the Australian Pharmaceutical Benefits Assessment Committee (PBAC) was founded in 1954, many countries have by now established similar bodies, including the National Institute for Health and Care Excellence (NICE) in the United Kingdom (UK) set up in 1999, the Institute for Quality and Efficiency in Health Care (IQWiG) in Germany set up in 2004, the National Evidence-Based Healthcare Collaborating Agency (HIRA) in Korea, the Health Intervention and Technology Assessment Program (HITAP) in Thailand as well as many others (Stafinski et al., 2011). At the 2014 World Health Assembly in Geneva, a resolution was adopted for the incorporation of health intervention and technology assessment to support Universal Health Coverage (UHC).

Priority setting in health care does not simply take place in the setting of health technology assessment agencies, however. Cabinets, government departments, health care agencies and local authorities all have a role in priority setting through their routine decisions on resource and budgetary allocations, decisions on capital spending, price negotiations with manufacturers on pharmaceutical products and medical devices as well as investments in the training of medical and para-medical staff. Courts play a role in adjudicating the extent to which some of these decisions, when contested by plaintiffs, conform to administrative, constitutional or international law. Hospitals and insurance agencies make decisions on which services to provide and to whom. And individual physicians are inevitably involved in making decisions on health priorities when they make treatment decisions with their patients. From boardroom to bedside the determination of priorities is implicit in an organized health care system.

The context of these decisions is one in which governments and insurance funders increasingly are seeking value for money in resource allocation. In high income countries the choices involved typically revolve around access to expensive therapies, sometimes of marginal advantage but which are thought important by particular groups. Approval and finance of such interventions raise considerable issues of policy choice, particularly in fixed budget systems where any positive decision necessarily involves an opportunity cost, often with direct implications for disadvantaged groups for whom the use of political voice may be harder. In middle and low income countries priority setting is increasingly seen to be central to securing universal access to reasonably comprehensive care of reliable quality (World Health Organization, 2014), but mechanisms for it are less established.

A popular mechanism for priority setting is health technology assessment (HTA). Here, it is important to distinguish between technology assessment as practised by HTA agencies, and the appraisal of assessment outcomes. While HTA is defined as a multidisciplinary undertaking that assesses effects, benefits, and harms of a health technology across a range of issues, including social, economic and 
ethical issues (see for example WHO, 2016), in practice the remit of HTA agencies is often limited to providing expert evaluations of the benefits and costs of health technologies according the predefined decision criteria and health economic methodologies such as cost effectiveness analyses. These processes are largely scientific, technocratic and expert-driven. The results of such processes need to be given meaning in the policy making arena. It is for this reason that the process of HTA assessment and appraisal are distinct from one another: "Assessment is the science that underlies HTA (i.e., the HTA study). Appraisal is the process by which the science is considered at the policymaking level" (Oliver et al., 2004: 4). This distinction reflects the fact that priority setting decisions give rise to contentious distributional conflicts that need to be resolved in the public space that includes avenues for deliberation (Landwehr, 2009).

Priorities can be set in different ways. The most frequently observed and frequently contested examples are concerned with decisions about which medicines or interventions to cover for provision or reimbursement. Controversies around expensive pharmaceuticals are familiar, but similar controversies can occur in relation to such interventions as renal replacement therapies. Priority setting also occurs around decisions to disinvest from relatively expensive interventions in order to release resources for most cost-effective uses, decisions that, for example, may pitch the priority to be given to urban hospitals against the priority to be given to rural public health. Priorities are also set, and in low and middle income countries are most commonly set, by failures to include certain social groups in the financial risk protection that universal health care allows.

Even in countries in which governments enjoy a high level of political legitimacy, priority decisions in health prompt challenges. Health policy makers or managers cannot assume that they can derive legitimacy for their decisions from the general legitimacy of the political system. Even when the choices meet formal conditions of due process, they can encounter public resistance. In high income countries, such resistance takes the form of campaigners, patient groups and industry contesting the decisions on cost effectiveness or on decisions to deny coverage or reimbursement of particular interventions. In low and middle income countries it may take the form of citizens protesting against the denial of basic services from the government. Where general government legitimacy is low, the stock of political capital that health policy makers can borrow from it in making controversial decisions may well be very low.

In this context, policy makers are exploring the potential for direct public participation to enhance legitimacy in the identification of priorities. New forms of public participation, for example the use of mini-publics like citizens' juries or deliberative polls, are being developed alongside the representation of members of the public in routine decision-making processes. However, alongside this top-down interest in participation, priority setting has also stimulated bottom-up forms of participation as patient groups, rights activists and others mobilize around the promise of universal health care.

The papers gathered together in this special issue of the Journal of Health Organization and Management explore the character, modes and implications of public participation in health care priority setting, examining empirically, analytically and normatively the contribution that public participation makes to priority setting and health care equity. These papers derive from a workshop held at the Brocher Foundation in Geneva in November 2015, which brought together scholars and policy makers from twelve different countries to share their experiences and understanding. This Introduction presents an overview of the issues that public participation in priority setting raises.

\section{Defining Public Participation in Priority Setting}


The term 'public participation' covers a variety of activities and practices, and no one definition is likely to secure universal assent. Our approach has been to follow the lead of Parry, Day and Moyser (1992: 16) in their path-breaking study of political participation in Britain and to define participation in health policy as a form of political participation, where political participation is defined as 'taking part in the processes of formulation, passage and implementation of public policies'. On this definition, public participation in priority setting involves individuals or groups taking part in processes of policy making that shape the determination of priorities in health care and the conditions of access of different groups in society. Political participation is thus collectivelyorientated and aimed at securing a decision on public policy or legal rules.

Closely related to the conceptualization of political participation is our understanding of what constitutes the 'political', which we derive from Lasswell's definition of politics as involving decisions about who gets what, when and how (Lasswell, 1936). Since priority setting and rationing in health care give rise to political conflicts over distributive consequences of decisions (e.g. Landwehr, 2009), they can be usefully thought of as decisions about who gets what, when and how. Using Lasswell's definition of politics in this way also underlines one of the normative rationales for public participation, namely that those affected by distributive decisions should be included in decisionmaking processes whose outcomes affect them.

The definition of 'public' lacks consensus (Abelson et al., 2007; Mitton et al., 2009). Does it refer to the general public, to patients, potential patients regarded as consumers or patient groups and associated activists? How do we treat the fact that public participation typically means not participation by the public as a whole but by selected persons, taken to be representative of the whole? These questions are more than just conceptual puzzles for policy analysts; they are also practical questions of public administration when designing or reforming participatory practices. For example, Australia's PBAC includes a 'consumer' representative while the Pharmaceutical Management Agency (PHARMAC) in New Zealand has a consumer advisory panel, made up of representatives or advocates of consumers. Patient groups play an important role in Thailand's HITAP. The German Federal Joint Committee, which makes decisions based on the HTA assessment of IQWiG, allows for patients to take part in discussions and submit petitions (G-BA, 2016). The patient representatives take part in deliberations and propose resolutions, but they do not have voting rights (Kieslich, 2015: 106). Similarly, as part of the Thai process for setting priorities for inclusion in the basic package of universal health coverage, representatives of patient groups can propose items for consideration. Public participation can therefore take a wide variety of forms, with different understanding of 'the public' affecting how decision-making is structured.

Public participation in the formal sense also includes institutionalized forms of consultation with the public, for example in cases where draft decisions or determination are put out to stakeholders for comment. Public participation in the making of policy also includes the use of mini-publics, in which selected members of the public come together for the purposes of deliberation in forums established by policy makers, to help shape policy and define choices. For example, NICE's Citizen Council represents a form of public participation in our sense. In all of these forms of public involvement, participation is institutionalized in some way, so that members of the public play a relatively well defined role, working through established procedures, and typically responding to policy agendas and issues that have been set by the administrative or political authorities.

Following Parry, Moyser and Day (1992: 18), we also include in public participation activities that they describe as 'unconventional', that is to say actions that are outside the confines of conventional politics and therefore of the formal policy process. Such activities include demonstrations, political strikes, boycotts, acts of interference with traffic and even instances of physical violence or riot. 
However, in some health care systems, as the analysis in a later paper shows (Slutsky et al., 2016), these types of activity are far from unconventional; in fact they represent a routine form of public participation in priority setting. They include, for example, street protests and demonstrations that aim to challenge the legitimacy of decisions about access to care or the availability of medicines. We label such participation 'contestatory', rather than 'unconventional' as in Parry, Moyser and Day, because the use of such protests is sometimes routine.

From this point of view, our definition of public participation is meant to be inclusive, covering both its formal, routine and institutionalized forms, on the one hand, and its contestatory forms on the other. However, it is exclusive in that it rules out various forms of involvement that are often considered important from the point of view of those interested in participatory health care. Of these, the most important is the involvement of patients in choices about their own personal care, a form of participation that is typically particular to the person concerned carrying no implications for public policy. It is restricted to what Mitton et al. (2009: 221) call the macro and meso levels of decision-making rather than the clinical level. Thus, when individual patients negotiate with their physician about the choice between surgery or watchful waiting, or a pregnant woman determines the choice between home or hospital delivery, these are forms of participatory involvement excluded from our discussion. Such exclusion is not intended to suggest that such practices are unimportant. Indeed, one of the principal ways in which health services may be transformed is through the cumulative effect of a large number of individual decisions made by patients. However, the decisions remain individual ones taken from a personal perspective (Dolan et al., 2003), and so are not directed towards the collective determination of public priorities.

It might be argued that this distinction between individual and collective is artificial in those cases of priority setting where public education (both government or non-government sanctioned) can shift personal choices from one form of treatment to another. Moreover, the use of administrative and legal challenges by individuals can have widespread policy implications. For example, in $1997 \mathrm{Mr}$ Soobramoney, who had kidney failure and other co- morbidities, appealed to the Constitutional Court of South Africa for the right to a kidney transplant, even though his medical condition was such that he was not eligible under the transplant guidelines of the treating hospital. His appeal was based on the grounds that failure to secure the transplant would breach his right, under Section 27(3) of the South African Constitution, that 'no one may be refused emergency medical treatment' and Section 11 that stipulates that 'everyone has the right to life'. In the particular case, the court decided that it should not interfere with the existing resource allocation policy of the hospital, ruling that Soobramoney's case was not an emergency (Constitutional Court of South Africa, 1997). However, had it decided to the contrary, there is no doubt that the individual case would have had widespread implications for health care resource allocation in South Africa, potentially requiring many other forms of medical care to be provided. As this example shows, even if an individual appellant is not aiming at a general change in law or policy, there can be cases where court decisions in an individual's case can have general ramifications.

Between individual and collective action there is clearly a continuum of activities and we accept that there is a fine line to be drawn as to when an individual legal challenge is to count as political participation. Sometimes an individual administrative or legal challenge simply affects the individuals involved, as is the case with individual funding requests in the United Kingdom's National Health Service or New Zealand's PHARMAC, where physicians on behalf of their patients request the funding of therapies that are not normally covered by the funders. Such types of challenge do not figure in our analysis, because they are not challenges to the policy but to the way that the policy operates in the individual case. Other legal challenges may have policy relevance, as in the 
Soobramoney case, even if that is not the intention of the appellant. And yet others may be individually related but are supported by more general political mobilization. If we were to exclude all forms of legal challenge, particularly legal challenge under constitutional provisions, entirely from the scope of public participation, we should miss an important element of the dynamics of mobilization in a number of countries. Conversely, to exclude the cases of action for purely individual reasons keeps the focus on the collective dimension of public participation.

A second type of participation excluded from our analysis is that involving survey responses and similar attempts to ascertain preferences. Such surveys include patient experience surveys, where the views of those who have used a service are elicited, but also include experimental results and discrete choice experiments. Such experiments "typically involve the presentation of a series of choices in which respondents are asked to choose one of two or more alternative scenarios, each representing a unique combination of specified attributes and levels of the treatment or service, under consideration" (Whitty et al., 2014: 59). An important aspiration of these experiments is to provide a sense of the relative priority to be given to alternatives. Our exclusion of these methods of public participation from our analysis is not because they are unimportant, or because they should be classified as research rather than patient involvement. They are part of the information that flows through a health care system and in that sense are an important component of decision-making on priorities. However, their policy dynamic is different from the forms of participation with which we are concerned, since they are typically the product of administrative processes. In this respect, they fall into a different category from patient and public representatives occupying seats on priority setting bodies or mobilizing in order to secure a change in policy. A similar point can be made about information collected through complaints mechanisms. These may be an important resource for policy makers (although typically they are not given sufficient attention), but they are not in themselves a means by which patients and the public participate in policy making. Similar points can also be made about the use of focus groups, which are often used to assess public reaction to issues, but are not themselves integrated into the public deliberative system.

An important form of public participation that straddles the divide between public deliberative system and individual survey response is the use of mini-publics (e.g. Goodin and Dryzek, 2006; Grönlund et al., 2014; Niemeyer, 2014; Ryan and Smith, 2014; Niemeyer, 2011). A mini-public is a group of lay persons selected so as to be descriptively 'representative' in some sense of a wider public and asked to deliberate about a policy issue and provide an opinion. They take different forms including citizens' juries, citizen panels, consumer forums or deliberative polls. Sometimes these approaches aim at consensus, as with citizens' juries, and sometimes they prompt individual responses to be aggregated, as with deliberative polls. Mini-publics are like surveys in that their function is typically to provide policy makers with information about public preferences and attitudes. However, they are unlike conventional surveys because they ask participants to deliberate about a general policy question, often from the point of view of a citizen rather than a patient, and come to a conclusion on that question. In some cases, as with NICE's Citizens Council, they are closely integrated into the decision-making system. In other cases, they may be ad hoc one-off events.

In summary, then, this special issue focuses on public participation that is collective in character, in the sense that the participation relates to a social, not personal, decision and is relevant to whole groups of people and not single individuals. It can take various forms both formal and institutionalized on the one hand, as with public representatives on decision- making bodies, and informal and contestatory on the other, as with organized demonstrations and protests. It also includes legal challenges, the significance of which go beyond the individual case. The use of mini- 
publics should also be included, both when they are routinely integrated into decision-making and when they ad hoc and one-off. In identifying these different forms of public participation, we are not supposing that they are mutually exclusive. Indeed, different forms of participation may come into play in relation to the same types of decision, as discussed in the next section.

\section{The Scope of Public Participation}

Public participation in health policy can affect a wide range of issues. Following Lomas (1997), however, it is possible to identify three broad types of question that can be addressed through public participation: decisions on overall levels of funding; decisions of principle on the type of services to be offered or reimbursed, including the principles used in health technology assessments; and decisions on the eligibility of different types of patients or groups. (Compare also Mitton et al., 2009: 223, who also add questions of monitoring and evaluation.)

Overall Funding. Health care spending is popular with citizens in democracies. However, opportunities for public participation on such decisions are typically limited, because they are bound up either with the wider public expenditure process in government or with the processes of determining contributions among the major social partners in social insurance systems. However, it is possible in principle to organize such discussions and one example is the Deliberative Poll on the future of the UK's National Health Service held on the service's fiftieth anniversary and organized by the Center for Deliberative Polling at the University of Texas, Social \& Community Planning Research (SCPR) and Channel 4 (Park et al. 1998; Parkinson 2006). Channel 4 broadcast four episodes about the poll on the weekend of 5-6 July 1998. More generally, however, public participation in such matters normally takes place through voting in elections and the competition for support by parties standing for office.

Principles of Service Coverage. The most visible forms of priority setting concern which medicines or procedures to provide or reimburse within the scope of public coverage. Which pharmaceuticals over and above the WHO Essential Medicines list should be covered? What should be included in primary health care benefit packages? How far should renal replacement therapy, heart transplants, bariatric surgery or infertility treatment be included? Such decisions cannot be avoided, even if they are only made implicitly, with potentially limited transparency, rather than explicitly. Disinvestment raises similar problems compounded by the fact that, where there are established services, individuals and patient groups will have acquired legitimate expectations in the availability of care.

Obviously, where public representatives sit in an official capacity on decision-making bodies, there is some form of public participation in such choices. However, the number of public members is necessarily limited, and each public member can quickly become an "institutionalized" expert. One of the ways in which policy makers have sought to extend public participation is through the use of mini-publics, which can provide a forum in which the principles of coverage can be debated by an informed lay public.

An illustrative example of public involvement through mini-publics of this sort is the Israeli Health Parliament, which was a meeting established by officials from the Ministry of Health, researchers from Tel Aviv University and members of the Zippori Center for Community Education (Guttman et al., 2008: 180). As part of the exercise there were six meetings held in six regional groups in community centres, and participants were asked their views on issues of equity (whether people should be allowed to pay to ensure their choice of doctor in publicly funded hospitals and whether the requirement of co-payment for medical services and medications provided through the National 
Health Insurance system should be continued) and rationing (how should 'life-saving' treatment be defined and what priority should be given to rare conditions).

In some cases, the discussions can become quite technical, for example the NICE Citizens Council discussed whether the standard time discount rate should be applied to assess the benefits of interventions when those benefits occurred at a relatively distant point in the future (NICE, 2011). Technology assessment can also prompt participation in the form of demonstrations protests and resort to the media. On more than one occasion there have been protests at the offices of NICE over particular decisions that the agency has made.

Decisions on Eligibility for Services. One of the ways in which services can be provided in relation to resources is by the denial of services to particular groups of people. Hospitals and clinics in particular localities may be closed or the scope of their services reduced. In relation to health technology assessment, questions can arise about the extent to which particular groups should be eligible or ineligible for services that are generally available. Thus, for instance, the NICE Citizens Council has been asked to examine how far age should be a relevant criterion of assessment (NICE, 2003) or whether self-inflicted diseases should be given lower weight in assessments.

Not all decisions on service provision need concern the availability of resources. Instead they may concern how best to use such resources as are available. For example, in the provision of some services there is a well-known trade-off between accessibility, which suggests small centres of care close to patients, and quality, which suggests concentrating care so that professionals improve their skills through dealing with large numbers. This sort of trade-off ought to take into account a number of considerations, and one of the ways of making a decision is to involve members of the public, or patients, in deliberating on alternative courses of action. Thus, early citizens' juries, financed by the King's Fund, were asked to consider the location of specialist cancer services, where the question of access versus quality typically emerges (Mclver, 1998). Decisions on services, particularly decisions to reduce or close services, are often controversial and so it is not surprising that they provoke public participation of the contestatory kind.

\section{Rationales for Public Participation}

Public participation in all its forms in priority setting is an empirical phenomenon, taking various forms in different health care systems. As far as rationales go, the emerging wisdom is that involving the public can increase the chances of successful policy implementation, manage public expectations, improve public understanding of complex policy problems and result in a more empowered citizenry (for example Lomas, 1997; Niemeyer, 2011). In light of existing barriers to PPI in priority setting (e.g. Goold et al., 2005) though, ascertaining whether these theoretical expectations translate into empirical actuality remains a challenging issue.

However, public participation also raises issues of social and political values that give rise to its underlying rationales. There are a number of strands of democratic theory that suggest that, if citizens take an active interest in matters of public service, then both instrumental and intrinsic values are served. Properly to evaluate the role of public participation in priority setting, then, requires us to examine the range of possible values that such participation may serve. Two sets of values that are likely to be particularly relevant to questions of priority setting: legitimacy and representation.

Democratic Legitimacy. Priority setting in health policy is an obviously important part of public decision-making, and public decisions require legitimation. One minimal notion of legitimacy is purely procedural, based on the principle that decisions are legitimate when they are made in 
accordance with legal and constitutional rules and conventions. For example, principles of good governance and due process require administrative decisions to be taken after consultation with affected parties. One way of understanding public participation is an extension of the existing obligation of governments to consult in order to enable individuals and groups to forward views and opinions in accordance with their interests.

However, since the rise of deliberative democratic theory in the 1970s and 1980s, theorists have advanced a more demanding standard than purely procedural legitimacy, summarized in Cohen's (1989: 22) claim that political outcomes are legitimate "if and only if they could be the object of free and reasoned agreement among equals". Studies of innovations in public involvement invoke this background of theory (Abelson et al., 2013: 1; Guttman, 2007: 411) as part of the rationale for increasing and improving public deliberation through the use of mini-publics. One central principle in deliberative theory is to move away from the normal pulling and hauling of competing political forces in procedures of policy consultation towards a more collectively-orientated and problemorientated basis of decision-making.

This concern with the deliberative quality of policy decisions is reinforced by observations on the weakness of conventional competitive party politics and modes of interest-group representation to accommodate adequately the scale of views, needs and equality issues to which challenging tradeoffs in health policy give rise. In a competitive party system there is an incentive for those campaigning to make incompatible promises, for example offering lower taxes or contributions and improved services. In consequence, citizens are rarely confronted by the trade-offs that are required by policy choice. "Public deliberation rests on the democratic principle that important societal decisions-particularly issues involving competing values and complex trade-offs-are best made by policymakers in partnership with an informed public" (American Institutes for Research, 2016).

New methods of public participation through mini-publics are sometimes seen as rectifying the imbalance of financial or human resources between different societal groups. For example, if a proposal is made to exclude an intervention from collective health coverage, then industry and producer groups are likely to be in a better position to make representations in a consultation than individuals. By contrast, if an effort is made to consult citizens through the use of mini-publics, then a more general perspective in terms of social values may be garnered.

However, the literature on deliberative democratic theory also raises complex questions about the extent to which instruments of deliberative democracy such as mini-publics can meet the requirements of legitimacy that are set out by deliberative democratic theorists. For example, Lafont (2015) explores the tensions between the conditions for high-quality deliberative processes, such as the participants being open to change their views and opinions as a result of deliberations, and the normative demand that participation processes be inclusive of the citizenry at large. She argues that "[...] even the most general necessary conditions for deliberation are best satisfied in small-scale face-to-face deliberation" (Lafont, 2015: 46). However, the make-up of such small-scale deliberations does not necessarily satisfy conditions of what constitutes legitimate representation as the representatives in these forums have neither been elected nor selected through democratic processes available to the non- participants who may be affected by the outcomes of deliberative processes (Parkinson, 2003). This raises complex questions about whether deliberative processes can, or should, be used as instruments to inform public policy making (Lafont, 2015).

The papers in this special issue underline these complexities. As Hunter et al. (2016) conclude, an underlying theme of the papers is the importance and the challenge of establishing legitimacy in health prioritization. Here, public participation may be thought of as part of the process of 
legitimation as distinct from contributing to the product of legitimacy. The latter is a matter for empirical investigation in order to explore whether theories of legitimacy in health care decisionmaking actually yield more acceptable decisions in the eyes of those affected (see Kieslich and Littlejohns, 2015), whereas the former is a trend, a goal, a demand and a fact in most health care systems, albeit in different forms. The different modes of public participation, be they orientated towards consensus or contestation (Weale, 2016), can support the decision-making process by illuminating additional perspectives and arguments that can be considered. Regardless of the form of public participation, behind the question of legitimacy is the important question of representation.

Better Representation. Conventional democratic politics, though based on the principle of representation, is biased against various forms of participation. Elected representatives are rarely representative of those whom they represent. If social characteristics (age, class, ethnicity, gender and so on) are related to political opinion, then a skew in the characteristics of elected representatives and public officials, relative to the population at large, runs the risk of neglecting important elements of public opinion. More generally, those who are politically active through parties and interest groups, which in the case of health care will include patient group representatives, are socially unrepresentative of the population at large.

It is partly for this reason that mini-publics have become popular in some discussions around public participation in health care. Mini-publics can be seen as a way of rectifying the imbalance of representation brought about through the selection processes inherent in electoral politics, although there are important caveats on whether this amounts to legitimate representation (e.g. Lafont, 2015; Parkinson, 2003). These caveats relate to the broader literature on how political representation is established and how it incorporates deliberative democratic norms (e.g. Mansbridge, 1999; Mansbridge, 2003; Parkinson, 2003; Pitkin, 1967; Phillips, 1995; Dryzek and Niemeyer, 2008). A large branch of this literature examines how political representatives relate to their constituents (Mansbridge, 2003). Traditional forms of representation are closely aligned with principal-agents models, where the agent (the political representative) represents the principal (the elector) through either a delegate or a trustee model of representation. Under the trustee model agents make decisions as they choose, whereas they follow the principals' instructions directly under the delegate model (Parkinson, 2003). These views of representation have been expanded to include more nuanced understandings of representation including, but not limited to, descriptive representation (Pitkin, 1967), surrogate representation (Mansbridge, 2003) and discursive representation (Dryzek and Niemeyer, 2008). While a detailed discussion of these forms of representations is beyond the scope of this paper, it is important to note the recurring questions in relation to representation. Who and what is represented? How are representatives selected and what is their role (Parkinson, 2003)? How are issues of power played out in deliberative forums?

A related consideration is diversity. Random sampling will enhance the diversity of social characteristics represented in deliberation on public policy, but it will not necessarily capture the views and opinions of small minorities who may not be included in a random sample. In some cases, for example, members of minorities have been purposively included in mini- public events in order to deal with this problem. Any concern with the politics of difference in priority setting will need to find some ways of overcoming the selection effects inherent in the policy process, and mini-publics seem to offer one way around this problem if they incorporate forms of descriptive representation, that is if individuals share characteristics or experiences with particular members of a societal group (Mansbridge, 2003; Pitkin, 1967). 
The question of diversity is also important because the price mechanism, which is one familiar way of dealing with diversity, is attenuated in the case of health care. For reasons including information asymmetry between physicians and patients the regulation of the market based on price mechanisms that follow demand and supply fails in the case of health care and it has to be modified or suspended and replaced with a collective alternative (Arrow, 1963). However, in restricting the operation of the price mechanism, those providing collectively-based universal health care lose the role of prices as a source of information about strength of patients, consumer and citizen preferences. If citizens are willing to pay for improvements in health care, they may have no way of signalling this fact in a system based upon administratively determined resource allocation. If voice is to stand in for exit in health services, then the question of how representative the voices are becomes important.

The question of the representativeness or otherwise of the voices that are heard in the priority setting process, and the lack of voices that may be missing, has important implications for the justice and fairness of the priorities that are set. An influential account of justice in health care resource allocation stresses the place of 'accountability for reasonableness' (Daniels, 1994; Daniels and Sabin, 2008). This approach assumes that disputes about priority setting cannot be resolved consensually, but they can be resolved procedurally. Provided decision- makers are willing to be open and transparent about their reasoning, offering grounds for their judgement that are public, reasonable and revisable, then resource allocation can be regarded as fair by virtue of meeting those procedural conditions. However, if political participation is unbalanced in representative terms, then the legitimacy of decisions based on procedural norms alone is called into question.

\section{Conclusion}

Public participation in priority setting is both a fact and a challenge. It is a fact because through various formal and contestatory routes it exists and plays a role in the way that decisions are made. It is a challenge because we have relatively little empirical evidence as to how it affects the decisions made, whether it "improves" decisions against some specified desirable criteria, and few attempts to assess the extent to which it conforms to democratic norms. This special issue is an attempt to address these issues through comparative cross- country analysis.

The first paper looks at patterns of public participation, and suggests a dynamic in which token formal inclusion leads to more active contestatory action (Slutsky et al., 2016). In the second paper, Kieslich et al. (2016) examine this dynamic through the analysis of decision-making on interventions for the management of Hepatitis $\mathrm{C}$, which has been a controversial priority setting issue in many countries. In a third paper, Weale (2016) focuses on the implications for democratic theory and argues that given the role of routinized contestation in some priority setting contexts, particularly in Latin America, South Korea and South Africa, we should move away from a focus on Habermasinspired ideals of consensus through mini- publics to look at ideas of radical democracy associated with Chantal Mouffe. Finally, Hunter et al. (2016) provide an analysis of the findings' implications for $\mathrm{PPI}$ in health priority setting and for the future research agenda.

\section{Acknowledgments}

This work was generously supported by the Brocher Foundation in Geneva, Switzerland, where the workshop on "Improving equitable access to health care through increasing patient and public involvement in prioritisation decisions" was held in November 2015. We thank the Brocher Foundation for hosting and funding this workshop. 
Katharina Kieslich and Peter Littlejohns are supported by the National Institute for Health Research (NIHR) Collaboration for Leadership in Applied Health Research and Care (CLAHRC) South London at King's College Hospital NHS Foundation Trust. The views expressed are those of the authors and not necessarily those of the NHS, the NIHR or the Department of Health.

Aviva Tugendhaft is supported by funding to PRICELESS SA from the international Decision Support Initiative (IDSI) through the Bill and Melinda Gates Foundation, grant number 740671.

We are grateful to the reviewers for their comments and suggestions on our manuscript.

\section{References}

Abelson, J., Giacomini, M., Lehoux, P. and Gauvin, FP. (2007), "Bringing 'the public' into health technology assessment and coverage policy decisions: From principles to practice", Health Policy, Vol. 82 No. 1, pp. 37-50.

Abelson, J., Blacksher, E.A., Li, K.K., Boesveld, S.E. and Goold, S.D. (2013), “Public Deliberation in Health Policy and Bioethics: Mapping an Emerging, Interdisciplinary Field", Journal of Public Deliberation, 9: 1, Article 6. Available at: http://www.publicdeliberation.net/jpd/vol9/iss1/art5/.

American Institutes for Research. (2016) "Public Deliberation: Bringing Common Sense to Complex Health Policy Issues", available at: http://www.air.org/resource/public-deliberation- bringingcommon-sense-complex-health-policy-issues (accessed 03 May 2016).

Arrow, K.J. (1963), "Uncertainty and the Welfare Economics of Medical Care", American Economic Review, Vol. 53 No. 5, pp. 941-973.

Burton, P., Whitty, J.A., Kendall, E., Ratcliffe, J., Wilson, A., Littlejohns, P. and Scuffman, P. (2014), "Public Participation: Methods Matter; A response to Boaz et al.", International Journal of Health Policy Management, 3: 355, doi: 10.15171/ijhpm.2014.108.

Cohen, J. (1989), "Deliberation and Democratic Legitimacy", in Hamlin, A. and Pettit, P. (Eds.), The Good Polity: Normative Analysis of the State, Basil Blackwell, Oxford, pp.17-34.

Constitutional Court of South Africa. (1997) "Thiagraj Soobramoney vs Minister of Health (KwazuluNatal)", available at: http://www.saflii.org/za/cases/ZACC/1997/17.pdf (03 May 2016).

Daniels, N. and Sabin, J.E. (2008), Setting limits fairly: learning to share resources for health. 2nd Edition, Oxford University Press, Oxford.

Daniels, N. (1994), "Four Unsolved Rationing Problems: A Challenge", The Hastings Center Report, Vol. 24 No. 4, pp. 27-29.

Daniels, N. (2008), Just Health: Meeting Health Needs Fairly, Cambridge University Press, Cambridge.

Dolan, P., Olsen, J.A., Menzel, P. and Richardson, J. (2003), "An inquiry into the different perspectives that can be used when eliciting preferences in health", Health Economics, Vol. 12 No. 7, pp. 545-551.

Dryzek, J.S. and Niemeyer, S. (2008), "Discursive Representation", American Political Science Review, Vol. 102 No. 4, pp. 481-493.

Fishkin, J.S. (1995), The Voice of the People: Public Opinion and Democracy, Yale University Press, New Haven. 
Gemeinsamer Bundesausschuss (G-BA). (2016) "Patient involvement", available at: http://www.english.g-ba.de/structure/patient/ (accessed 28 April 2016).

Goodin, R.E. and Dryzek, J.S. (2006), "Deliberative Impacts: The Macro-Political Uptake of MiniPublics", Politics \& Society, Vol. 34 No. 2, pp. 219-244.

Grönlund, K., Bächtiger, A. and Setälä, M. (Eds.). (2014), Deliberative Mini-Publics - Involving Citizens in the Democratic Process, ECPR Press, Colchester.

Guttmann, N. (2007), "Bringing the Mountain to the Public: Dilemmas and Contradictions in the Procedures of Public Deliberation Initiatives That Aim to Get "Ordinary Citizens" to Deliberate Policy Issues", Communication Theory, 17, pp. 411-438.

Guttmann, N., Shalev, C., Kaplan, G., Abulafia, A., Bin-Nun, G., Goffer, R., Ben-Moshe, R., Tal, O., Shani, M. and Boaz, L. (2008) "What Should Be Given Priority - Costly Medications for Relatively Few People or Inexpensive Ones for Many? The Health Parliament Consultation Initiative in Israel", Health Expectations, Vol. 11, pp. 177-188.

Hunter, D.J., Kieslich, K., Staniszewska, S., Tumilty, E., Weale, A. and Williams, I. (2016), "Public Involvement in Health Priority Setting: Future Challenges for Policy, Research and Society", Journal of Health Organization and Management, This issue.

Kieslich, K. (2015), "Paradigms in Operation: Pharmaceutical Benefit Assessments in England and Germany", PhD thesis, available at http://discovery.ucl.ac.uk/1463556/1/PhD_Thesis_K_Kieslich_17.03.2015.pdf (accessed 28 April 2016).

Kieslich, K., Ahn, J., Badano, G., Chalkidou, K., Cubillos, L., Hauegen, RC., Krubiner, C., Littlejohns, P., Lu, L., Pearson, S., Rid, A., Whitty, JA, Wilson, J. (2016), "New Antivirals for Hepatitis C: A Case for Stronger Public Involvement in Health Coverage Decisions?", Journal of Health Organization and Management, This issue.

Kieslich, K. and Littlejohns, P. (2015), "Does accountability for reasonableness work? A protocol for a mixed methods study using an audit tool to evaluate the decision-making of clinical commissioning groups in England", BMJ Open, doi:10.1136/bmjopen-2015-007908.

Lafont, C. (2015), "Deliberation, Participation and Democratic Legitimacy: Should Deliberative Minipublics shape Public Policy?”, The Journal of Political Philosophy, Vol. 23 No. 1, pp. 40-63.

Landwehr, C. (2009) "Democratic and technocratic policy deliberation", Critical Policy Studies, Vol. 3 Nos. 3-4, pp. 434-439.

Lasswell, H.D. (1936), Politics: Who gets what, when, how, Whittlesey House, New York.

Littlejohns, P. and Rawlins, M. (Eds.) (2009), Patients, the Public and Priorities in Healthcare, Radcliffe Publishing, Oxford and New York.

Lomas, J. (1997), "Reluctant Rationers: Public Input to Health Care Priorities", Journal of Health Services Research and Policy, Vol. 2 No. 2, pp. 103-11.

Mansbridge, J. (1999), "Should Blacks Represent Blacks and Women Represent Women? A Contingent "Yes", The Journal of Politics, Vol. 61 No. 3, pp. 628-657. 
Mansbridge, J. (2003), "Rethinking Representation", American Political Science Review, Vol. 97, No. 4, pp. 515-528.

Mclver, S. (1998), Healthy Debate?, The King's Fund, London.

Mitton, C., Smith, N., Peacock, S., Evoy, B. and Abelson, J. (2009), "Public participation in health care priority setting: A scoping review", Health Policy, Vol. 91 No. 3, pp. 219-228.

NICE Citizen Council. (2003) "NICE Citizen Council Report on Age", available at: https://www.nice.org.uk/Media/Default/Get-involved/Citizens- Council/Reports/CCReport02Age.pdf (accessed 05 March 2016).

NICE Citizen Council. (2011) "How should NICE assess future costs and health benefits?", available at: https://www.nice.org.uk/Media/Default/Get-involved/Citizens-

Council/Reports/CCReport15Discounting.pdf (accessed 05 March 2016).

Niemeyer, S. (2011), "The Emancipatory Effect of Deliberation: Empirical Lessons from Mini-Publics", Politics \& Society, Vol. 39 No. 1, pp. 103-140.

Niemeyer, S. (2014), "Scaling up deliberation to mass publics: Harnessing Mini-Publics in a Deliberative System", in Grönlund, K., Bächtiger, A. and Setälä, M. (Eds.), Deliberative Mini-Publics Involving Citizens in the Democratic Process, ECPR Press, Colchester, pp. 177-203.

Oliver, A., Mossialos, E. and Robinson, R. (2004), "Health technology assessment and its influence on health-care priority setting", International Journal of Technology Assessment in Health Care, Vol. 20 No. 1, pp. 1-10.

Park, A., Jowell, R. and McPherson, S. (1998) The Future of the National Health Service: Results from a Deliberative Poll. London: Social and Community Planning Research. available at: http://citeseerx.ist.psu.edu/viewdoc/download;jsessionid=75775E40EEA7EA8FB438DCC34 36976BA?doi=10.1.1.176.6478\&rep=rep1\&type=pdf (accessed 30 March 2016).

Parkinson, J. (2003), "Legitimacy Problems in Deliberative Democracy”, Political Studies, Vol. 51, pp. 180-196.

Parkinson, J. (2006), Deliberating in the Real World: Problems of Legitimacy in Deliberative Democracy, Oxford University Press, Oxford.

Parry, G., Moyser, G. and Day, N. (1992), Political Participation and Democracy in Britain, Cambridge University Press, Cambridge.

Phillips, A. (1995), The Politics of Presence, Clarendon Press, Oxford.

Pitkin, H.F. (1967), The Concept of Representation, University of California Press, Berkeley.

Ryan, M. and Smith, G. (2014), "Defining Mini-Publics", in Grönlund, K., Bächtiger, A. and Setälä, M. (Eds.), Deliberative Mini-Publics - Involving Citizens in the Democratic Process, ECPR Press, Colchester, pp. 9-27.

Slutsky, J., Tumilty, E., Max, C., Lu, L., Tantivess, S., Hauegen, RC., Whitty, JA, Weale, A., Pearson, S., Tugendhaft, A., Wang, H., Staniszewska, S., Weerasuriya, K., Ahn, J. and Cubillos, L. (2016), "Patterns of Public Participation: Opportunity Structures and Mobilization from a Cross-National Perspective", Journal of Health Organization and Management, This issue. 
Stafinski, T., Menon, D., Philppon, D.J. and McCabe, C. (2011), "Health technology funding decisionmaking processes around the world: the same, yet different", Pharmacoeconomics, Vol. 29 No. 6, pp. 75-95.

Weale, A. (2016), "Between Consensus and Contestation", Journal of Health Organization and Management, This issue.

World Health Organization (WHO). (2016), "Health technology assessment", available at: http://www.who.int/medical_devices/assessment/en/ (accessed 27 April 2016).

Whitty, J.A., Burton, P., Kendall, E. And Racliffe, J., Wilson, A., Littlejohns, P. and Scuffman, P. (2014a), "Harnessing the Potential to Quantify Public Preferences for Healthcare Priorities through Citizen's Juries", International Journal of Health Policy and Management, Vol. 3 No. 2, pp. 57-62.

Whitty, J.A., Lancsar, E., Rixon, K., Golenko, X. and Ratcliffe, J. (2014b), "A systematic review of stated preference studies reporting public preferences for healthcare priority setting", The Patient, Vol. 7 No. 4, pp. 365-86. 